УДК 316.4.06:314.422

$10.17213 / 2075-2067-2021-2-130-141$

\title{
ПОТЕРИ РОССИЙСКОЙ МОЛОДЕЖИ \\ В КОНТЕКСТЕ ПОВЕДЕНЧЕСКИХ ФАКТОРОВ РИСКА В 2000-е ГОДЫ
}

\author{
(C) 2021 г. В. Г. Семенова ${ }^{* * * *}$, С. А. Вангородская ${ }^{* * *}$ \\ "Институт демографических исследований \\ Федерального научно-исследовательского социологического центра РАН, \\ 2. Москва, Россия \\ ** ФГБУ «Центральный научно-исследовательский институт \\ организации и информатизации здравоохранения" \\ Министерства здравоохранения Российской Федерации, г. Москва, Россия \\ *** Белгородский государственный национальный исследовательский университет, \\ 2. Белгород, Россия
}

Цель исследования: анализ потерь российской молодежи на фоне возрастной эволюции поведенческих факторов риска.

Методологическую основу исследования составили основные положения соииологии жизни и здоровья, социологии молодежни и сочиологии риска, позволившие подтвердить выдвинутую ранее гипотезу о взаимосвязи межнду иенностью жизни и показателями смертности российскоймолодељси.

Результаты исследования. Приводится анализ тенденций и закономерностей смертности российской молодежи в период 2000-2019 г2. На основе статистических данных выявлено снижение общей смертности молодежи, изменение ее структуры, а также эволюиия ее картины с возрастом. Отмечено, что, несмотря на положительную динамику смертности в молодых возрастах, пристального внимания требуют внешние причины смерти, обусловленные не только склонностью молодежи к риску, но в значительной степени преуменьшением цеенности человеческой жизни на уровне личности и общества. Рассмотрена эволючия поведенческих факторов риска, предопределяющих различия в характере смертности российской молодежи младших и старших возрастных групп.

Перспективы исследования. Предложена система мер, реализация которых позволит обеспечить снижение поведенческих факторов риска и повыпение ценности человеческой жизни в сознании россиян.

Ключевые слова: молодежь; ценность жизни; смертность молодежи; смертность по причинам; внешние причины смерти; социальные риски.

\section{LOSSES OF RUSSIAN YOUTH IN THE CONTEXT OF BEHAVIORAL RISK FACTORS IN THE 2000S}

\section{(C) 2021 V. G. Semyonova ${ }^{*, * *}$, S. A. Vangorodskaya ${ }^{* * * *}$}

"Institute of Demographic Research of the Federal Research Sociological Center of the Russian Academy of Sciences, Moscow, Russia ${ }^{* *}$ Federal Research Institute for Health Organization and Informatics of the Ministry of Health of the Russian Federation, Moscow, Russia ${ }^{* * *}$ Belgorod State University, Belgorod, Russia 
The purpose of the study: analysis of the losses of Russian youth against the background of age-related evolution of behavioral risk factors.

The methodological basis of the study was based on the main provisions of the sociology of life and health, the sociology of youth and the sociology of risk, which allowed us to confirm the previously put forward hypothesis about the relationship between the value of life and the mortality rates of Russian youth.

The results of the study. The analysis of trends and patterns of mortality of Russian youth in the period 2000-2019 is given. On the basis of statistical data, a decrease in the overall mortality of young people, a change in its structure, as well as the evolution of its picture with age are revealed. It is noted that, despite the positive dynamics of mortality at young ages, close attention is required to external causes of death, due not only to the propensity of young people to risk, but, to a large extent, underestimation of the value of human life at the level of the individual and society. The article considers the evolution of behavioral risk factors that determine the differences in the nature of mortality of Russian youth in younger and older age groups.

Research prospects. A system of measures is proposed, the implementation of which will ensure the reduction of behavioral risk factors and increase the value of human life in the minds of Russians.

Key words: youth; value of life; youth mortality; mortality by causes; external causes of death; social risks.

Введение. Задача увеличения численности российского населения, заявленная в программных документах Российской Федерации как одна из приоритетных, предполагает реализацию комплекса мер, направленных, с одной стороны, на увеличение рождаемости, а с другой - на сокращение смертности. При этом, по мнению российских ученых, именно сокращение смертности, причем смертности в молодых возрастах, является «наиболее эффективным направлением стабилизации демографической ситуации в стране» [11].

Анализ масштабов и основных причин смертности российской молодежи постоянно находится в центре внимания отечественных исследователей $[12,13]$. Смерть в любом возрасте трагична, но, как справедливо отмечают А.Е. Иванова и соавторы, «смерть, наступившая преждевременно, это потеря не только человеческой жизни, но и недопроизводство валового продукта, потеря инвестиций в образование и профессиональную подготовку» [6, с. 14].

Несмотря на улучшение демографической ситуации в большинстве регионов Российской Федерации, смертность российской молодежи по-прежнему остается достаточно высокой и в ряде регионов превышает средние значения по стране. При этом, согласно данным статистики, основным «источником потерь среди молодежи являются внешние причины: в настоящее время потери российской молодежи - населения 15-29 лет обусловлены травмами и отравлениями на 2/3 в мужской и почти наполовину в женской популяции» [14, с. 5].

Оценивая динамику смертности российской молодежи в 2000-е годы, необходимо отметить, что основные потери в этой группе, с одной стороны, формируются как результат совокупного воздействия социально-экономических, культурно-исторических, эпидемиологических и иных факторов, с другой - обусловлены спецификой социально-демографических и психологических характеристик молодежи. Это требует внимания со стороны всех социальных институтов, заинтересованных в улучшении качественных и количественных характеристик человеческого потенциала в России.

Это делает актуальной цель настоящего исследования: оценку потерь российской молодежи на фоне возрастной эволюции поведенческих факторов риска. 
Результаты исследования. В 2000е годы динамику смертности молодежи (по последним данным, в эту возрастную группу входят лица 15-34 лет) можно разделить на два периода: в 2000-2005 гг. у мужчин в первые 2 года наблюдалось некоторое снижение, а затем рост показателей, у женщин же тренды были устойчиво негативными, вследствие чего первая половина нулевых годов оказалась существенно более напряженной для молодых женщин, смертность которых выросла на 11,7\% против $1,3 \%$-го роста у их ровесников. Второй период (2005-2019 гг.), во-первых, характеризовался стабильно позитивными тенденциями и в мужской, и в женской популяции, однако темпы этих позитивных тенденций в женской популяции оказались меньшими, нежели у мужчин (2-кратное снижение против 2,6-кратного).

Вследствие этого 2000-е годы оказались более выигрышными для мужчин, нежели

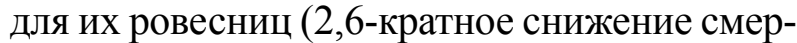
тности против 44,8\%-го) (рис. 1).

При этом нельзя не отметить, что рост смертности в первой половине нулевых годов был обусловлен взрослыми молодыми людьми - лицами 25-34 лет, в большинстве своем завершившими образование, получившими устойчивые профессиональные позиции, создавшим семьи: потери в этой возрастной группе в 2000-2005 гг. выросли на $13,5 \%$ в мужской и более чем на четверть (на 25,2\%) в женской популяции против $21,2 \%$ и 9,8\%-го снижения среди 15-24-летних. Интересно, что после 2005 г. подоб- ная разнонаправленность трендов между 2 возрастными группами молодежи исчезает: сформировавшиеся тренды, во-первых, во всех половозрастных группах позитивные, во-вторых, и в мужской, и в женской популяции их темпы среди 15-24- и 25-34-летних практически совпадают (2,5- и 2,6-кратное снижение в мужской и 2,1- и 2-кратное - в женской популяции).

Вследствие подобной динамики в 2000е годы и в мужской, и в женской популяции ситуация развивалась более успешно среди 15-24-летних, нежели среди 25-34-летних, причем независимо от возраста, у мужчин более благоприятно, чем у женщин.

Возникает вопрос: какими именно причинами определялись отмеченные тренды смертности в основных половозрастных группах российской молодежи?

Позитивные тренды смертности юношей 15-24 лет в 2000-2005 гг. были обусловлены всеми ведущими причинами смертности, кроме болезней органов пищеварения, потери от которых выросли почти на треть. В женской популяции наблюдался рост смертности не только от болезней органов пищеварения, потери от которых у 15-24-летних выросла почти на $2 / 3$, но и от инфекционных болезней и болезней системы кровообращения (соответственно на 13,5\% и 9,3\%).

После 2005 г. позитивные тенденции смертности 15-24-летних и в мужской, и в женской популяции определялись всеми ведущими причинами, при этом темпы снижения смертности в мужской популяции превышали таковые в женской от всех мужчины

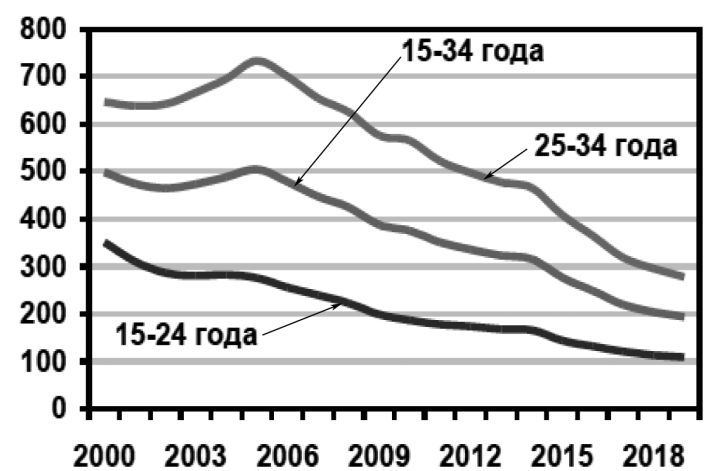

женщины

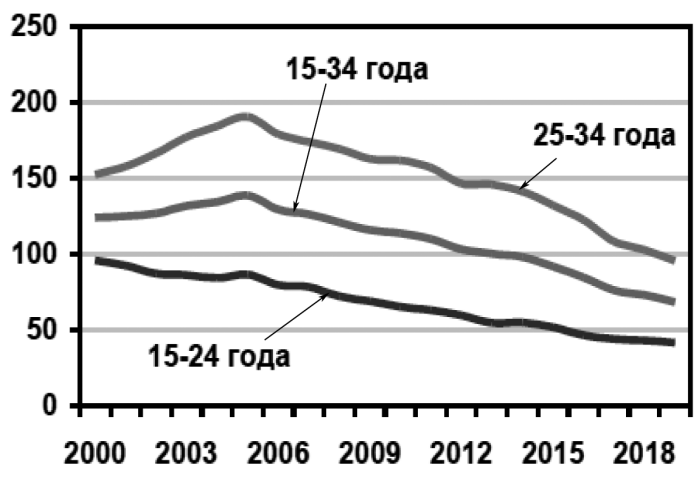

Рис. 1. Динамика смертности российской молодежи в 2000-е годы (стандартизованный коэффициент на 100 тыс. населения) 
причин, кроме новообразований $(38,8 \%$ против 41,9\%). Смертность от ведущих в этой возрастной группе внешних причин снизилась в 2,7 раза в мужской и 2,4 раза - в женской популяции. Интересно, что если у мужчин инфекционные болезни оказались лидером по темпам позитивных тенденций, то у женщин - относительным аутсайдером (4,9-кратное снижение против 2-кратного).

В целом в 2000-е годы позитивные тенденции среди 15-24-летних определялись всеми ведущими причинами, при этом темпы снижения варьировали достаточно существенно: так, у мужчин на фоне 3,2-кратного снижения общей смертности максимально снизились показатели от инфекционных болезней и болезней органов дыхания (в 6,7 и 4,7 раза), минимально - на 45,6\% — от новообразований. В женской популяции 2,3-кратное снижение общей смертности было обусловлено в первую очередь опережающими темпами снижения смертности от внешних причин (в 2,7 раза), а также от болезней органов дыхания и симптомов, признаков и неточно обозначенных состояний (в 2,5 и 2,4 раза соответственно).

Среди «взрослой» группы молодежи (25-34-летних) ситуация складывалась менее благополучно: так, негативные тенденции первой половины нулевых годов и в мужской, и в женской популяции были обусловлены всеми ведущими причинами смерти, за исключением новообразований, смертность от которых у мужчин снизилась на 5,6\%. Максимальные темпы роста смертности (соответственно в 2,2 и 2,7 раза) наблюдались для болезней органов пищеварения, на втором месте у женщин оказались инфекционные болезни (рост на 82,1\%).

В 2005-2019 гг. позитивные тенденции были обусловлены всеми ведущими причинами у мужчин, у женщин исключением оказались только инфекционные заболевания, смертность от которых выросла почти на треть (против 37,5\%-го снижения в мужской популяции).

При этом и среди мужчин, и среди женщин минимальными темпами снижалась смертность от новообразований (на 30,9\% и 28,1\%), максимальными - от болезней органов дыхания (в 4,2 и 3,1 раза соответс- твенно). Подчеркнем, что смертность от лидирующих в этих возрастах внешних причин и болезней системы кровообращения снизилась кратно и в мужской (в 3 и 2,5 раза), и в женской популяции (3- и 2-кратно).

Позитивные итоги 2000-х годов и среди мужчин, и среди женщин 25-34 лет в мужской популяции определялись всеми ведущими причинами смерти, в женской исключением оказались инфекционные болезни и болезни органов пищеварения, смертность от которых выросла соответственно в 2,4 раза и на 40,9\% (против $20,6 \%$ - и 6,1\%-го снижения у мужчин). Максимальными темпами в период исследования и в мужской, и в женской популяции снижались потери от болезней органов дыхания, внешних причин и неточно обозначенных состояний.

Подобная динамика не могла не изменить структуру смертности российской молодежи в 2000-е годы.

Эволюция структуры смертности молодежи за 2000-2019 гг. во всех половозрастных группах характеризовалась сходными закономерностями: на фоне снижения значимости болезней органов дыхания, внешних причин и неточно обозначенных состояний происходило нарастание вклада новообразований и болезней системы кровообращения, с одной стороны, и болезней органов пищеварения и особенно инфекционных болезней - с другой (исключением оказались только 15-24-летние юноши, у которых доля инфекционной смертности снизилась с 3,1\% до $1,5 \%)$.

При этом трансформация структуры смертности оказалась более глубокой среди «взрослой» молодежи: так, у мужчин доля внешних причин, в течение всего периода занимавших лидирующие позиции, снизилась с примерно 2/3 общей смертности до половины, при этом значимость инфекционной смертности практически удвоилась (рост с 5,9\% до $11 \%$ ), вследствие чего в настоящее время инфекционные заболевания вошли в тройку ведущих причин смерти, наравне с болезнями системы кровообращения, занимавшими второе место: их вклад вырос с $11 \%$ до 14,2\%. Принципиально (с 3,1\% до 6,7\%) выросла также значимость болезней органов пищеварения. 
Еще более отчетливо эти закономерности проявились в женской популяции: вклад внешних причин снизился примерно с половины до четверти общей смертности 25-34-летних, при этом на второе место вышли инфекции, доля которых выросла с 5,1 \% до 19,6\%.

Отметим, что среди 15-24-летних, где рост инфекционной смертности не приобрел такие масштабы, эволюция структуры смертности выглядит существенно более благополучной: так, у мужчин вследствие роста вклада ранг болезней системы кровообращения поднялся с 3-го до 2-го места, новообразований - с 5-го до 3-го места, в женской популяции ранжировка ведущих причин практически не изменилась, однако в ведущей триаде доля внешних причин снизилась с $62,8 \%$ до 54,1 \% (1-е место), новообразований и сердечно-сосудистых заболеваний — выросла с $7,3 \%$ до $8,7 \%$ и с $5,6 \%$ до $8,2 \%$ (2-е и 3 -е места соответственно).

В этом контексте крайне интересным представляется нозологический профиль половозрастной смертности молодежи в 2019 г.: из табл. 1 видно последовательное (особенно у женщин) нарастание с возрастом доли всех ведущих патологий на фоне снижения значимости внешних причин (исключением являются только новообразования у мужчин, вклад которых снизился с 5,2\% у 15-19-летних до 3,8\% у 30-34-летних).

Обсуждая полученные результаты в контексте влияния самосохранительного поведения на здоровье российской молодежи, можно отметить, с одной стороны, снижение значимости внешних причин, с другой - рост числа экзогенных (во всяком случае, предотвратимых) патологий (инфекционные болезни и болезни органов пищеварения).

Еще более очевидным представляется возрастной вектор указанных экзогенных патологий: нельзя не отметить, что у 30-34-летних мужчин доля инфекций существенно превышает вклад новообразований, у их ровесниц - оказывается выше, нежели значимость и новообразований, и сердечно-сосудистых заболеваний (табл. 1).

Если же проследить возрастной вектор смертности молодежи от болезней органов пищеварения, то можно указать, что если у 15-19-летних юношей в триаду ведущих па- тологий входили непроходимость прямой кишки, острый панкреатит и язва 12-перстной кишки, а у их ровесниц - неинфекционный энтерит, колит, перитонит и другие циррозы печени, то среди 30-34-летних ведущую роль играли другие циррозы и алкогольный цирроз печени, а также острый панкреатит: эти патологии, особенно в подобной комбинации, не могут не ассоциироваться с поведенческими факторами риска, в первую очередь, с алкоголем.

Обсуждение результатов исследования. Анализируя динамику смертности российской молодежи в указанный период, следует отметить несколько обстоятельств: во-первых, снижение общей смертности молодежи, во-вторых, изменение ее структуры в 2000-е годы, и, в-третьих, эволюцию ее картины с возрастом.

Первые обстоятельства свидетельствуют как о количественном, так и о качественном улучшении ситуации среди молодежи как таковой, к которой логично отнести подростков 15-19 лет и 20-25-летних молодых людей, среди них существенную часть занимает студенчество. В этой возрастной группе очевидно как стабильное снижение смертности, так и улучшение ее картины, выразившееся в снижении значимости экзогенных причин, включая травмы и отравления на фоне роста значимости причин эндогенных (новообразований и, с некоторой осторожностью, болезней системы кровообращения).

Несколько иная ситуация сложилась среди «взрослой» молодежи (25-34 года), родившихся в самый критический период российской истории, когда страна переживала коренную ломку всей системы ценностей. Это, безусловно, отразилось и на самой молодежи, формируя у представителей данной группы «плюрализм мировоззренческих установок и отсутствие единства в отношении базовых ценностей» [5, с. 88].

Отметим, что позитивные тенденции смертности в этой возрастной группе сформировались только после 2005 г., когда страна вышла из затянувшегося на 15 лет социально-экономического кризиса. Представляется показательным, что именно в этой возрастной группе, помимо безусловно позитивного снижения значимости внешних причин 
(являющихся одним «из двух главных классов причин смерти факторов, определяющих отставание России от большинства развитых стран по ожидаемой продолжительности жизни» [7, с. 87]), наблюдается резкое возрастание вклада инфекционных болезней и болезней органов пищеварения, что в контексте поведенческих факторов риска означает проблемы сексуального характера (ВИЧ/ СПИД), а также злоупотребление алкоголем (алкогольный и другие циррозы печени, острый панкреатит).

Принятое в настоящее время объединение в группу молодежи лиц от 15 до 34 лет во многом затрудняет конкретизацию факторов риска, присущих молодежи в целом: нельзя забывать, что 15-летние подростки могут быть детьми 34-летних, что не может не предполагать разные модели поведения и как следствие - разные факторы риска внутри социальной группы «молодежь».

Показательной в этом контексте представляется эволюция возрастной структуры смертности молодежи: если у подростков речь идет об острых рисках, приводящих к потерям от внешних причин, то у 30-34-летних аномально высокой оказывается значимость инфекционных заболеваний (напомним, что у мужчин они занимали 3-е место, в женской популяции - 2-е, причем их вклад, с одной стороны, существенно превышал долю онкологии и ССБ (20\% против $15 \%)$, с другой относительно незначительно уступал значимости внешних причин (24\% против $20 \%)$ ).

Таблица 1

Возрастной профиль структуры смертности российской молодежи в 2019 г.

\begin{tabular}{|l|c|c|c|c|c|c|c|c|c|}
\hline \multirow{2}{*}{\multicolumn{1}{|c|}{ Причины смерти }} & \multicolumn{2}{|c|}{$15-19$ лет } & \multicolumn{2}{|c|}{$20-24$ года } & \multicolumn{2}{|c|}{$25-29$ лет } & \multicolumn{2}{|c|}{$30-34$ года } \\
\cline { 2 - 10 } & $\begin{array}{c}\text { На } 100 \\
\text { тыс. }\end{array}$ & $\%$ & $\begin{array}{c}\text { На } 100 \\
\text { тыс. }\end{array}$ & $\%$ & $\begin{array}{c}\text { На } 100 \\
\text { тыс. }\end{array}$ & $\%$ & $\begin{array}{c}\text { На } 100 \\
\text { тыс. }\end{array}$ & $\%$ \\
\hline \multicolumn{7}{|c|}{ Мужчины } \\
\hline Все причины & 77,2 & 100 & 140,5 & 100 & 201,1 & 100 & 354,9 & 100 \\
\hline Инфекционные болезни & 0,6 & 0,8 & 2,6 & 1,9 & 16,2 & 8,1 & 44,8 & 12,6 \\
\hline Новообразования & 4 & 5,2 & 5,8 & 4,1 & 7,4 & 3,7 & 13,6 & 3,8 \\
\hline $\begin{array}{l}\text { Б-ни системы } \\
\text { кровообращения }\end{array}$ & 4,4 & 5,7 & 11,4 & 8,1 & 22,2 & 11 & 56,8 & 16 \\
\hline Б-ни органов дыхания & 1,1 & 1,4 & 2 & 1,4 & 4 & 2 & 10,3 & 2,9 \\
\hline Б-ни органов пищеварения & 0,8 & 1 & 2 & 1,4 & 9,2 & 4,6 & 27,8 & 7,8 \\
\hline $\begin{array}{l}\text { Неточно обозначенные } \\
\text { состояния }\end{array}$ & 3,4 & 4,4 & 7,3 & 5,2 & 11,7 & 5,8 & 20,6 & 5,8 \\
\hline Внешние причины & 54,7 & 70,9 & 102,7 & 73,1 & 122,3 & 60,8 & 165,2 & 46,5 \\
\hline \multicolumn{7}{|c|}{ Женщины } \\
\hline Все причины & 36,2 & 100 & 46,5 & 100 & 69,6 & 100 & 121,3 & 100 \\
\hline Инфекционные болезни & 0,6 & 1,7 & 3,6 & 7,7 & 12,9 & 18,5 & 24,4 & 20,1 \\
\hline Новообразования & 3,1 & 8,6 & 4,1 & 8,8 & 8,2 & 11,8 & 18,3 & 15,1 \\
\hline $\begin{array}{l}\text { Б-ни системы } \\
\text { кровообращения }\end{array}$ & 2,4 & 6,6 & 4,4 & 9,5 & 8,8 & 12,6 & 18,2 & 15 \\
\hline Б-ни органов дыхания & 1 & 2,8 & 1,3 & 2,8 & 2,2 & 3,2 & 4 & 3,3 \\
\hline Б-ни органов пищеварения & 0,5 & 1,4 & 1,3 & 2,8 & 5 & 7,2 & 13,6 & 11,2 \\
\hline $\begin{array}{l}\text { Неточно обозначенные } \\
\text { состояния }\end{array}$ & 1,5 & 4,1 & 2,5 & 5,4 & 2,4 & 3,4 & 4,1 & 3,4 \\
\hline Внешние причины & 21,7 & 59,9 & 23,1 & 49,7 & 23,2 & 33,3 & 29,2 & 24,1 \\
\hline
\end{tabular}


Вопросы вызывает и высокая значимость сердечно-сосудистых болезней в этих возрастах (16\% и 15\% соответственно): в этой возрастной группе еще не могли сформироваться дистрофические процессы, делающие физиологически обусловленными потери от болезней системы кровообращения в старческих возрастах, таким образом, не может не возникать вопрос об экзогенных, поведенческих факторах риска.

Анализируя картину смертности молодежи в 2000-годы, следует исходить из нескольких постулатов: во-первых, из преждевременного характера подавляющей части смертей в этих возрастах и, во-вторых, от их обусловленности экзогенными факторами, даже если речь идет о соматических заболеваниях. При этом экзогенными факторами риска в этой возрастной группе, как правило, являются риски поведенческие.

Обсуждая модели поведения молодежи, нельзя исключить еще один, специфически важный для данной возрастной группы фактор: молодежь во все времена и у всех народов склонна к более рискованному поведению, нежели лица старших возрастных групп. Это определяется психофизиологическими особенностями молодежи, недооценкой последствий определенных форм поведения, переоценкой своих возможностей и накладывается на характеристики «современного общества, в котором риск выступает как часть действительности» [9, с. 45].

Именно склонность к рискованному поведению обусловливает доминирование в структуре смертности представителей данной социально-демографической группы внешних причины смерти, предопределяющих существенное отставание России от развитых стран по показателям смертности и продолжительности жизни и включающих в себя убийства, самоубийства, несчастные случаи и пр.

С другой стороны, нельзя не учитывать и модели поведения, принятые в каждом конкретном социуме, а именно - стиль жизни общества в целом. Если общей нормой жизни общества является соблюдение законов от соблюдения правил дорожного движения до заповеди «не убий», социальные лифты, здоровый образ жизни как норма, низкое потребление алкоголя, неприятие наркотиков, то этот стиль жизни формируется и среди молодежи, и наоборот. Поэтому ценностные ориентиры молодежи являются своеобразным отражением ценностей общества в целом.

В контексте изучаемой проблематики существенный интерес представляет подход к оценке потерь российской молодежи (в первую очередь, от внешних причин) c позиций ценности человеческой жизни. По мнению сторонников данного подхода [14, 17], «все потери от внешних причин обусловлены либо неосторожным ... поведением конкретных людей, либо недостатками работы социальных институтов ... Таким образом, все потери от внешних причин можно ассоциировать, прямо или косвенно, с недооценкой ценности человеческой жизни в личностном либо общественном сознании» $[14$, с. 6].

Ценность человеческой жизни является предметом анализа в рамках аксиологии, социальной антропологии, философии и социологии жизни $[1,8,10,15,16]$ и выступает в качестве одной из главных характеристик цивилизованного общества. Ценность жизни в том или ином обществе складывается из соблюдения некоторой совокупности правил и снижения конкретных рисков, в первую очередь, поведенческих. Следовательно, именно на основе значимости факторов риска и обусловленных ими потерь можно судить о реальной ценности человеческой жизни в индивидуальном и коллективном сознании на каждом из этапов развития общества.

В России низкая ценность человеческой жизни обусловлена совокупным воздействием культурно-исторических, социально-экономических, политических, а также религиозных факторов, выступающих «в прошлом основными формирующими жизненное поведение элементами» [4, с. 56] и оказывающих непосредственное влияние на показатели здоровья и продолжительности жизни российского населения. Большую часть истории Россия характеризовалась доминированием архаичного стиля жизни и общинной психологии, что в сочетании с многочисленными войнами предопределило специфику «культурного кода» россиян [2], программируя коллективное сознание на «короткую, но яркую и геройскую» жизнь [3]. 
К началу XX века Россия все еще оставалась преимущественно аграрной страной с высокой долей (до $80 \%$ ) неграмотного населения. О том, как сработала совокупность этих факторов, свидетельствуют результаты проведенной в 1897 году первой Всероссийской переписи населения, выявившей крайне низкую (в сравнении с европейскими странами) продолжительность жизни в России.

Признание жизни вообще и индивидуального существования в частности в качестве одной из базовых ценностей общества произошло только в XX веке и стало следствием объективных процессов модернизации и трансформации современного общества. Причем, как отмечает С.И. Трунев, «безусловное доминирование указанной ценности в культурах большинства европейских стран и Америки приходится приблизительно на его вторую половину» $[16$, c. 118$]$.

Что касается России, то здесь не все так однозначно. Несмотря на повышение уровня жизни россиян, формирующегося с начала 2000-х годов, ценность человеческой жизни, и сегодня предопределяющая отставание России от большинства развитых стран по уровню заболеваемости и смертности населения, по-прежнему невелика. Это в значительной степени обусловлено масштабами социального неравенства (в том числе в получении образования, выступающего одним из основных факторов, влияющих на уровень смертности во всех возрастных группах), неопределенностью будущего, а также нестабильностью социальной среды, сопряженной с высоким уровнем внешних угроз. Особо необходимо отметить незавидное положение старшего поколения россиян, которое не способствует формированию в общественном сознании привлекательного образа старости и склоняет молодых людей к выбору поведения, не ориентированного на перспективу и не предполагающего сознательных долгосрочных «инвестиций» в укрепление здоровья и увеличение продолжительности жизни.

Заключение. Результаты проведенного анализа позволяют сформулировать ряд вы- водов и рекомендаций. Во-первых, основные потери российской молодежи являются результатом совокупного воздействия социально-экономических, культурно-исторических, эпидемиологических и иных факторов. Особая роль принадлежит поведенческим факторам риска, предопределяющим динамику и изменение структуры смертности в молодых возрастах.

Во-вторых, среди молодежи с возрастом происходит эволюция поведенческих факторов риска: если в младших возрастах речь идет преимущественно об их острых формах, то среди «взрослой» молодежи - о факторах риска, обусловленных не столько сиюминутными опасностями, сколько всем стилем жизни, включающим и опасное сексуальное поведение, и, как минимум, злоупотребление алкоголем.

В-третьих, доминирование класса внешних причин в структуре смертности российской молодежи актуализирует проблему повышения ценности жизни на уровне индивидуума и общества в целом. Учитывая полидетерминированную природу ценности жизни, представляется необходимым основные усилия государства направить на повышение образовательного уровня населения, разработку и реализацию комплексной системы мер по минимизации поведенческих факторов риска на уровне индивида и общества, а также на формирование привлекательного образа старости, что невозможно без смены приоритетов социальной политики в первую очередь в сторону повышения уровня и качества жизни представителей старших возрастных групп и населения в целом.

B-четвертых, любая система мер, направленных на снижение смертности молодежи, должна носить адресный характер и, следовательно, затрагивать каждую конкретную возрастную группу. И если среди лиц 15-24 лет эти меры должны быть преимущественно направлены на острые, сиюминутные поведенческие факторы риска, которыми обусловлены потери от внешних причин, то среди 25-34-летних необходимо, в первую очередь, формировать стиль поведения, направленный на снижение алкоголизации и наркомании в обществе. 


\section{Литература}

1. Баева Л. В. Ценностные основания индивидуального бытия: Опыт экзистенциальной аксиологии: Монография. - М.: Прометей, МПГУ, 2003. — 240 с.

2. Бочаров В.В. Молодость и старость в традиционной русской культуре (о книге Григорьевой И.А. и др. «Пожилые в современной России: между занятостью, образованием и здоровьем») // Социологические исследования. — 2017. - №1. - С. 159-163.

3. Вангородская С.A. Отношение к смерти в современном обществе: культурно-исторические особенности и влияние на самосохранительное поведение // Научные ведомости Белгородского государственного университета. Сер. Философия. Социология. Право. - 2019. - Т. 44. - №3. - C. 386-395.

4. Вебер M. Избранные произведения; пер. с нем. / Сост., общ ред. и послесл. Ю.Н. Давыдова; предисл. П.П. Гайденко. М.: Прогресс, 1990. - 880 с.

5. Гугуева Д. А., Фетисова О.В. Ценности современной российской молодежи в реальном и виртуальном обществах // Гуманитарий Юга России. — 2016. - Т. 21. — №5. C. 85-92.

6. Иванова А.Е. Семенова В.Г. Лопаков К. В., Михайлов А. Ю., Сабгайда Т. П., Землянова Е.В., Запорожченко В.Г., Евдокушкина Г.Н. Перспективы снижения смертности в Москве с учетом реализации мер демографической политики [Электронный ресурс]// Социальные аспекты здоровья населения: электронный научный журнал. - 2016. №50 (4). - С. 1-35. - Режим доступа: http:// vestnik.mednet.ru/content/view/760/30/lang.ru/ (Дата обращения: 10.03.2021).

7. Кваша Е., Харькова Т., Юмагузин В. Смертность от внешних причин в России за полвека // Демографическое обозрение. 2014. - T. 1. - №4. - С. 68-95.

8. Коваленко А. М. Ценность жизни в молодежной среде российского общества // Гуманитарий Юга России. - 2017. - Т. 6. №6. - C. 232-241.

9. Комбарова Е. В. Особенности социального риска молодежи в условиях современного российского общества // Среднерусский вестник общественных наук. - 2010. №1. - C. 44-49.
10. Краснобаева-Черная Ж. В. Аксиологический феномен жизни во фразеологии: жизнь как ценность и жизнь как система ценностей // Вестник ВГУ. Лингвистика и межкультурная коммуникация. - 2015. — №4. C. 31-35.

11. Римашевская Н.M. Русский крест [Электронный ресурс] // Природа. - 1999. №6. - Режим доступа: http://vivovoco. astronet.ru/VV/JOURNAL/NATURE/06 99/ RUSSDEMO.HTM (Дата обращения: 11.03.2021).

12. Рязаниев С.В., Семенова В.Г., Иванова А.Е., Сабгайда Т.П., Евдокушкина Г.Н. Демографические последствия социальных девиаций российской молодежи// Вестник Российской академии наук. - 2019. T. 89. - №3. - C. 221-231.

13. Семенова В.Г. Обратный эпидемиологический переход в России. - М.: ЦСП, 2005. - 235 c.

14. Семенова В.Г., Иванова А.Е., Сабгайда Т.П., Ввдокушкина Г.Н., В Запорожченко В.Г. Потери российской молодежи от внешних причин и факторы, их определяющие [Электронный ресурс] // Социальные аспекты здоровья населения: электронный научный журнал. - 2019. - №65 (6). C.1-35. - Режим доступа: http://vestnik. mednet.ru/content/view/1117/30/lang.ru/ (Дата обращения: 11.03.2021).

15. Тощенко Ж. T. Социология жизни как теоретическая концепция // Социологические исследования. - 2015. - №1. - С. 106-116.

16. Трунев С. И. Жизнь как ценность: проблемы и противоречия // Философия и общество. - 2008. - №4. - С. 118-125.

17. Юмагузин В. В., Винник М. В. Факторы смертности от внешних причин и пути ее снижения: опыт экспертного интервью [Электронный ресурс] // Социальные аспекты здоровья населения: электронный научный журнал. 2014. - №4 (38). - С. 1-14. - Режим доступа: http://vestnik.mednet.ru/content/view/595/30/ lang.ru/ (Дата обращения: 11.03.2021).

\section{References}

1. Baeva L.V. Cennostnye osnovanija individual'nogo bytija: Opyt jekzistencial'noj aksiologii: Monografija [Value bases of individual existence: The experience of existential 
axiology: a monograph]. - Moscow: Prometej, MPGU, 2003. - 240 p.

2. Bocharov V. V. Molodost' i starost' v tradicionnoj russkoj kul'ture (o knige Grigor'evoj I.A. $\mathrm{i}$ dr. «Pozhilye v sovremennoj Rossii: mezhdu zanjatost'ju, obrazovaniem i zdorov'em») [Youth and old age in traditional Russian culture (about the book by Grigorieva I.A. et al. «The elderly in modern Russia: between employment, education and health»)] // Sociologicheskie issledovanija [Sociological researches]. — 2017. №1. - Pp. 159-163.

3. Vangorodskaja S. A. Otnoshenie k smerti v sovremennom obshhestve: kul'turno-istoricheskie osobennosti i vlijanie na samosohranitel'noe povedenie [Attitude to death in modern society: cultural and historical features and influence on self-preserving behavior] // Nauchnye vedomosti Belgorodskogo gosudarstvennogo universiteta. Ser. Filosofija. Sociologija. Pravo [Scientific Bulletin of the Belgorod State University. Ser. Philosophy. Sociology. Pravo]. — 2019. Vol.44. - №3. - Pp. 386-395.

4. Veber M. Izbrannye proizvedenija; per s nem. [Selected works; trans. from German.]/ Sost., obshh red. i poslesl. Ju. N. Davydova; predisl. P.P. Gajdenko. - Moscow: Progress, 1990. - $880 \mathrm{p}$.

5. Gugueva D.A., Fetisova O.V. Cennosti sovremennoj rossijskoj molodezhi v real'nom i virtual'nom obshhestvah [The values of modern Russian youth in real and virtual societies] // Gumanitarij Juga Rossii. — 2016. — Vol. 21. №5. - Pp. 85-92.

6. Ivanova A.E. Semenova V.G. Lopakov K. V., MihajlovA. Ju., Sabgajda T.P., Zemljanova E.V., Zaporozhchenko V.G., Evdokushkina G.N. Perspektivy snizhenija smertnosti $\mathrm{v}$ Moskve $\mathrm{s}$ uchetom realizacii mer demograficheskoj politiki [Prospects for reducing mortality in Moscow taking into account the implementation of demographic policy measures] [Jelektronnyj resurs] // Social'nye aspekty zdorov'ja naselenija: jelektronnyj nauchnyj zhurnal [Social aspects of population health: electronic scientific journal]. - 2016. - №50 (4). - Pp. 1-35. - URL: http://vestnik.mednet.ru/content/view/760/30/ lang.ru/ (Date accessed: 10.03.2021).

7. Kvasha E., Har'kova T., Jumaguzin V. Smertnost' ot vneshnih prichin v Rossii za polveka [Mortality from external causes in Russia for half a century] // Demograficheskoe obozrenie
[Demographic review]. — 2014. - Vol. 1. №4. - Pp. 68-95.

8. Kovalenko A.M. Cennost' zhizni v molodezhnoj srede rossijskogo obshhestva [The value of life in the youth environment of the Russian society] // Gumanitarij Juga Rossii. — 2017. Vol. 6. - №6. - Pp. 232-241.

9. Kombarova E. V. Osobennosti social'nogo riska molodezhi $\mathrm{v}$ uslovijah sovremennogo rossijskogo obshhestva [Peculiarities of social risk youth in the conditions of modern Russian society] // Srednerusskij vestnik obshhestvennyh nauk [Bulletin of the Central Russian social Sciences]. - 2010. — №1. — Pp. 44-49.

10. Krasnobaeva-Chernaja Zh. V. Aksiologicheskij fenomen zhizni vo frazeologii: zhizn' kak cennost' i zhizn' kak sistema cennostej [Axiological phenomenon of life in phraseology: life as valuable and life as a system of values] // Vestnik VGU. Lingvistika i mezhkul'turnaja kommunikacija [Bulletin of the VSU. Linguistics and intercultural communication]. — 2015. №4. - Pp. 31-35.

11. Rimashevskaja N.M. Russkij krest [Russian cross] [Jelektronnyj resurs] // Priroda [Nature]. - 1999. — №6. — URL: http://vivovoco. astronet.ru/VV/JOURNAL/NATURE/06 99/ RUSSDEMO.HTM(Date accessed: 11.03.2021).

12. Rjazancev S. V., Semenova V.G., Ivanova A.E., Sabgajda T.P., Evdokushkina G. N. Demograficheskie posledstvija social'nyh deviacij rossijskoj molodezhi [The demographic implications of social deviance Russian youth]// Vestnik Rossijskoj akademii nauk [Bulletin of the Russian Academy of Sciences]. — 2019. Vol. 89. - №3. - Pp. 221-231.

13. Semenova V.G. Obratnyj jepidemiologicheskij perehod v Rossii [The Inverse epidemiological transition in Russia]. - Moscow: CSP, 2005. - $235 \mathrm{p}$.

14. Semenova V.G., IvanovaA.E., Sabgajda T.P., Evdokushkina G.N., Zaporozhchenko V.G. Poteri rossijskoj molodezhi ot vneshnih prichin i faktory, ih opredeljajushhie [Losses of Russian youth from external causes and factors determining them] [Jelektronnyj resurs] // Social'nye aspekty zdorov'ja naselenija: jelektronnyj nauchnyj zhurnal [Social aspects of population health: electronic scientific journal]. - 2019. — №65 (6). — Pp. 1-35. - URL: http://vestnik.mednet.ru/content/view/1117/30/ lang.ru/ (Date accessed: 11.03.2021). 
15. Toshhenko Zh. T. Sociologija zhizni kak teoreticheskaja koncepcija [Sociology of life as a theoretical concept] // Sociologicheskie issledovanija [Sociological research]. — 2015. №1. - Pp. 106-116.

16. Trunev S. I. Zhizn' kak cennost': problemy i protivorechija [Life as a value: issues and controversies] // Filosofija i obshhestvo [Philosophy and society]. - 2008. — №4. - Pp. 118-125.

17. Jumaguzin V.V., Vinnik M.V. Faktory smertnosti ot vneshnih prichin i puti ee snizhen- ija: opyt jekspertnogo interv'ju [Factors of mortality from external causes and ways to reduce it: the experience of the expert interviews] [Jelektronnyj resurs] // Social'nye aspekty zdorov'ja naselenija: jelektronnyj nauchnyj zhurnal [Social aspects of population health: electronic scientific journal]. — 2014. — №4 (38). Pp. 1-14. - URL: http://vestnik.mednet.ru/ content/view/595/30/lang.ru/ (Date accessed: 11.03.2021).

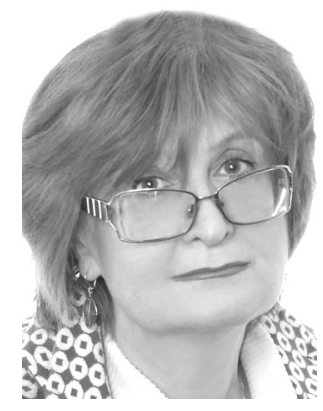

Семенова Виктория Георгиевна - доктор экономических наук, главный научный сотрудник Отдела здоровья и самосохранительного поведения Института демографических исследований Федерального научно-исследовательского социологического центра Российской академии наук.

Semyonova Victoria Georgievna - Doctor of Economic Sciences, Chief Researcher of the Department of Health and Self-preservation Behavior of the Institute of Demographic Research of the Federal Research Sociological Center of the Russian Academy of Sciences.

119333, г. Москва, ул. Фотиевой, 6, корп. 1

6 Fotievoj str., bld. 1, 119333, Moscow, Russia

E-mail: vika-home@yandex.ru 


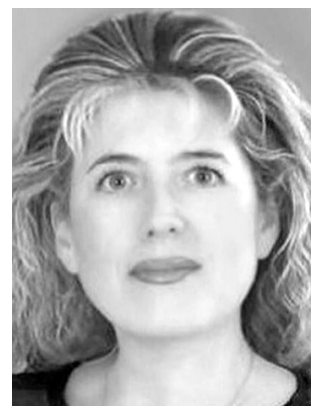

Вангородская Светлана Анатольевна - кандидат социологических наук, доцент кафедры социальных технологий и государственной службы Института экономики и управления Белгородского государственного национального исследовательского университета.

Vangorodskaya Svetlana Anatolyevna - Candidate of Sociological Sciences, Associate Professor of the Department of Social Technologies and Public Administration of the Institute of Economics and Management of the Belgorod State National Research University.

308015, г. Белгород, ул. Победы, 85

85 Pobedy st., 308015, Belgorod, Russia

E-mail: Vangorodskaya@bsu.edu.ru 